\title{
Prevalence of and risk factors for refractive error: a cross-sectional study in Han and Mongolian adults aged 40-80 years in Inner Mongolia, China
}

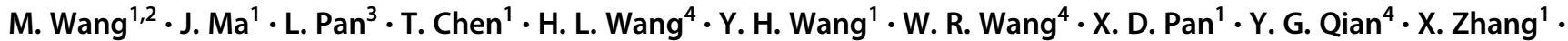 \\ Y. Zhong ${ }^{1} \cdot$ G. L. Shan ${ }^{3}$
}

Received: 12 August 2018 / Revised: 5 December 2018 / Accepted: 26 April 2019 / Published online: 3 June 2019

(c) The Royal College of Ophthalmologists 2019

\begin{abstract}
Objectives To assess the prevalence of and risk factors for refractive error (RE) in Han and Mongolian adults aged 40-80 years in Inner Mongolia in China and to identify ethnic differences in RE between these populations.

Methods Our cross-sectional study is part of the China National Health Survey (CNHS). The age-adjusted prevalence of RE in Han and Mongolian adults aged 40-80 in Inner Mongolia were compared. A multivariable logistic regression model was used to identify risk factors.

Results Among 2090 people, the age-adjusted prevalence of myopia $(\mathrm{SE}<-0.5 \mathrm{D})$, hyperopia $(\mathrm{SE}>0.5 \mathrm{D})$, high myopia $(\mathrm{SE}<$ $-6.0 \mathrm{D}$ ) and astigmatism (cylinder $\geq 0.5 \mathrm{D}$ ) were $29.4 \%$ (95\% confidence interval (CI), 27.4-31.3\%), 28.4\% (95\% CI, 26.4-30.5\%), 3.6\% (95\% CI, 2.8-4.4\%) and 65.9\% (95\% CI, 63.9-67.9\%), respectively. The age-adjusted prevalence of myopia in the Han population was higher than that in the Mongolian population $(31.8 \%$ vs. $23.0 \%, p<0.001)$, but the prevalence of hyperopia was lower $(25.8 \%$ vs. $35.3 \%, p=0.002)$. In the multivariable logistic regression, ethnicity was associated with myopia $(p=0.001)$ and hyperopia $(p=0.001)$. Myopia was also associated with age, time spent in rural areas $(p<0.001)$ and middle/high school and undergraduate/graduate education levels ( $p=0.027$ and $p<0.001$, respectively, compared with lower education levels). Additionally, age, height $(p=0.015)$ and pterygium $(p=0.014)$ were associated with hyperopia.

Conclusions Ethnicity is closely related to RE in Inner Mongolia in mainland China. Our study investigates differences in prevalence of and risk factors for RE between the Han and Mongolian populations, which could not be explained by differences in the risk factors investigated in this study.
\end{abstract}

\section{Introduction}

Refractive error (RE) is one of the most common ocular disorders. A review exploring the prevalence of RE between

These authors contributed equally: M. Wang, J. Ma

Supplementary information The online version of this article (https:// doi.org/10.1038/s41433-019-0469-0) contains supplementary material, which is available to authorised users.

Y. Zhong

yzhong_eye@163.com

$\triangle$ G. L. Shan

guangliang_shan@163.com

1 Department of Ophthalmology, Peking Union Medical College Hospital, Chinese Academy of Medical Sciences \& Peking Union Medical College, Beijing, China
1990 and 2010 indicated that 108 million people worldwide are affected by RE [1]. According to a study in the United States from 1999 to 2002 that involved 13,265 people aged 12 years and older, RE accounts for nearly $80 \%$ of visual impairments [2]. RE is considered to be the fourth priority within the policies of VISION 2020 regarding combating visual dysfunction [3].

In the past few decades, environmental factors have been widely believed to be associated with the development of myopia [4, 5]. A number of single-nucleotide

2 School of Medicine, Tsinghua University, Beijing, China

3 Department of Epidemiology and Statistics, Institute of Basic Medical Sciences, Chinese Academy of Medical Sciences \& Peking Union Medical College, Beijing, China

4 Inner Mongolia Center for Disease Control and Prevention, Hohhot, Inner Mongolia Autonomous Region, China 
polymorphisms (SNPs) have been identified to be associated with myopia, but most of them are not conclusively related to myopia [6]. The prevalence of myopia varies worldwide [7]. It is unknown whether the different distributions of RE are the result of different racial genetic backgrounds or culture-specific environmental influences [8]. The Chinese population is composed of individuals of Han ethnicity (91.51\%) and 55 ethnic minorities [9]. The Inner Mongolia Autonomous Region is located in Northern China, and Han and Mongolian individuals constitute 96\% of the population in Inner Mongolia. As a typical nomadic people mainly living in Mongolia and northern China, Mongolians are critical in the culture and genetic admixture of modern Eurasia through the rapid expansion of the Mongolian Empire 1000 years ago [10]. The previous data of our health survey revealed that the risk of hypertension was higher in the Mongolian population than in the Han population in Inner Mongolia [11]. Other studies have suggested that in the Mongolian population, the risk of cardiovascular diseases is higher than in the Han population $[12,13]$, but the risk of stroke is lower [14]. Moreover, there is some evidence suggesting that the difference in the risk of diseases might be based on the genetic heterogeneity [1517] and different lifestyles such as dietary habits [18] between the Han and Mongolian populations.

The Mongolian population in Inner Mongolia in Mainland China have the same ethnic background and similar lifestyles as people in Mongolia. A national health survey performed in Mongolia involving 1800 Mongolian people revealed that the prevalence of myopia (defined as a spherical equivalent (SE) $<-0.5 \mathrm{D}$ ) was $17.2 \%$, which was much lower than that in other East Asian populations, such as Chinese Singaporeans, in whom the prevalence was $38.7 \%$ [19]. One article published in 2015 compared central corneal thickness and curvature between Han and Mongolian populations in Inner Mongolia, and no difference was found [20]. Until now, no study has compared the prevalence of and risk factors for RE between Han and Mongolian populations in the same region. Our study is the first a cross-sectional study to compare the prevalence of RE in Han and Mongolian populations in Inner Mongolia in mainland China and further investigate the risk factors for myopia and hyperopia.

\section{Materials and methods}

\section{Study population}

The China National Health Survey (CNHS) was conducted by the Chinese Academy of Medical Sciences to evaluate the Chinese Physiological Constant and Health Condition. The part we reported on in this study was conducted in the Inner
Mongolia Autonomous Region in 2014. According to the level of urbanisation, four locations were randomly chosen for sampling, including a large city (Hohhot, $\left.40.83^{\circ} \mathrm{N}\right)$, a midsize city (Jining District of Ulanqab League, $41.03^{\circ} \mathrm{N}$ ), county seats (Wuyuan County of Bayannur City, $40.10^{\circ} \mathrm{N}$; West Ujimqin Banner of Xilingol League, $44.58^{\circ} \mathrm{N}$ ) and relevant rural sections. Sampling details can be found in the report of CNHS [21]. This study was conducted according to the tenets of the Declaration of Helsinki. Ethical approval was received from the Bioethics Committee at the Chinese Academy of Medical Sciences. Written informed consent was obtained from each participant after a full explanation of the nature and possible consequences of the study was provided.

\section{Inclusion and exclusion criteria}

The cluster sampling method was used in the CNHS. The ratio of Han to Mongolian participants was similar to the natural proportion of the population distribution in the Inner Mongolian Autonomous Region. As part of the National Health Survey, our study included 2222 participants aged 40-80 years old, and 2090 of them completed a questionnaire, a routine physical examination and eye examination. We only recruited people who had lived in their current residence for more than 1 year and excluded psychiatric patients, pregnant women and active-duty soldiers. Only participants with both Han parents or both Mongolian parents were included in our study.

\section{Data collection}

\section{Questionnaire and routine physical examination}

A questionnaire regarding demographic information and health history was administered during a comprehensive interview conducted by trained interviewers. The questionnaire collected information about age, sex, ethnicity, occupation, birthplace, current residence, migration date, education level, smoking and drinking history, occupational and leisure-time physical activity, and medical history, including hypertension and diabetes status. Routine physical examinations included assessments of height, weight, blood pressure, and fasting blood glucose. Height was measured to the nearest $0.1 \mathrm{~cm}$ using a fixed stadiometer, and weight was measured to the nearest $0.1 \mathrm{~kg}$ in a standing position via bioelectrical impendence analysis (BIA) with a commercially available body composition analyser (BC420, TANITA, Japan) with the participants wearing light clothes. Systolic and diastolic blood pressure were measured with a digital automatic blood pressure monitor, and the average of three measurements was recorded. After fasting overnight for at least $8 \mathrm{~h}$, blood samples were drawn, immediately processed, refrigerated, 
transferred and assessed at the laboratory of the General Hospital of Chinese Peoples' Liberation Army in Beijing. Body mass index (BMI) was calculated using the formula weight $(\mathrm{kg}) /$ height $(\mathrm{m})^{2}$.

\section{Ocular examination}

Ocular examinations were performed by two well-trained ophthalmologists with no significant differences in the consistency testing performed in the preliminary study. Visual acuity was measured with a logarithm of the minimum angle of resolution E chart (Wehen Co., Ltd., Guangzhou, China) at 4 metres and recorded together with whether the corrective lenses were used. An Auto Ref/ Keratometer (ARK-510A, Nidek Co., Ltd., Tokyo, Japan) was used to measure noncycloplegic refraction and corneal curvature radius. The anterior segment of the eye was examined with a portable hand-held slit-lamp (KJ5S2, Suzhou Kangjie Medical Co. Ltd., Jiangsu, China).

\section{Stratification standards}

All participants were divided into 5 age groups (40-44, $45-49,50-54,55-59$, and older than 60 years). Participants were divided into three groups based on education level, including primary school or less, middle/high school and undergraduate/graduate.

In terms of smoking history, participants were divided into never smokers and ever-smokers (which included current smokers and former smokers). Similarly, participants were divided into two categories regarding alcohol consumption: never-drinkers and ever-drinkers. Occupational and leisure-time physical activity were merged into activity level, which was categorised as three levels: low, moderate and high activity.

\section{Definitions of RE}

In our study, myopia was defined as $\mathrm{SE}<-0.5 \mathrm{D}$, and hyperopia was defined as $\mathrm{SE}>0.5 \mathrm{D}$. Astigmatism was defined as $\geq 0.5 \mathrm{D}$ of the cylinder. Myopia was further divided into mild, moderate and high (mild and moderate: $\mathrm{SE} \geq-6.0 \mathrm{D}$; high: $\mathrm{SE}<-6.0 \mathrm{D})$.

\section{Statistical analysis}

There was a high correlation between right and left eyes (Spearman's correlation test, $p<0.0001, r=0.872$ ). Similar results between right and left eyes were found during the statistical analysis; thus, only the results from the right eye were reported for conciseness. The $\chi^{2}$ test and Mann-Whitney $U$ test were used to compare the demographic differences between Han and Mongolian populations. The $\chi^{2}$ test was used to evaluate the differences in RE distributions between ethnicities among different age groups. The age-standardised prevalence was based on the Sixth National Population Census of the People's Republic of China. Multivariable logistic regression analysis was performed to identify the risk factors for RE. Multiple logistic regression models were developed with $\mathrm{RE}$ as a dichotomous dependent variable and relevant predictors as covariates. The potential risk or protective factors considered were ethnicity, age, sex, height, time spent in rural areas, education level, activity level, presence of pterygium and smoking habits. Indicators were chosen for the potential association with RE according to previous reports. Height has been indicated to be related to axial length [22-26]. It remains controversial whether nicotine intake is a protective factor or a risk factor for RE [27-29]. All coefficients were adjusted for other covariates that were included in the multiple logistic regression analysis. Analysis of all the participants was conducted first, and then separate analyses of Han and Mongolian populations were performed.

All probabilities were two-sided and were considered statistically significant at $p<0.05$. Statistical analysis was performed using Stata/SE 15.1 (StataCorp, USA) and Statistical Analysis System (SAS) version 9.4; figures were created using Prism 7.0a (Graphpad Software Inc, USA).

\section{Results}

\section{Characteristics of Han and Mongolian adults}

According to the inclusion and exclusion criteria, 2090 participants aged 40-80 years were involved in the final analysis (Table 1). The age composition and height distribution were similar between the Han and Mongolian populations in both sexes. A greater percentage of Han individuals than Mongolian individuals were currently living (male, $90.80 \%$ vs. $84.81 \%, p=0.012$; female, $92.37 \%$ vs. $88.76 \%, p=0.043$ ) or were born (male, $46.99 \%$ vs. $17.30 \%, p<0.0001$; female, $47.55 \%$ vs. $26.33 \%, p<$ $0.0001)$ in an urban area.

\section{Prevalence of RE in Han and Mongolian populations}

The age-adjusted prevalence of myopia, hyperopia, high myopia and astigmatism were $29.4 \%$ (95\% confidence interval (CI), 27.4-31.3\%), 28.4\% (95\% CI, 26.4-30.5\%), $3.6 \% \quad(95 \%$ CI, $2.8-4.4 \%)$ and $65.9 \% \quad(95 \% \quad \mathrm{CI}$, 63.9-67.9\%), respectively. The prevalence of different types of RE differed between Han and Mongolian populations. The age-adjusted prevalence of myopia and high myopia were higher in the Han population than in the Mongolian population (myopia, $31.8 \%$ vs. $23.0 \%$, 
Table 1 Characteristics of 2090 participants

\begin{tabular}{|c|c|c|c|c|c|c|}
\hline & Male & & & Female & & \\
\hline & $\begin{array}{l}\text { Han } \\
n=598\end{array}$ & $\begin{array}{l}\text { Mongolian } \\
n=237\end{array}$ & $P$-value & $\begin{array}{l}\text { Han } \\
n=917\end{array}$ & $\begin{array}{l}\text { Mongolian } \\
n=338\end{array}$ & $P$-value \\
\hline Age (y) & $54.13 \pm 9.50$ & $53.61 \pm 9.20$ & 0.510 & $51.92 \pm 9.14$ & $51.72 \pm 8.63$ & 0.994 \\
\hline Age range & & & 0.506 & & & 0.962 \\
\hline $40-44$ & $100(16.72)$ & $43(18.14)$ & & $232(25.30)$ & $83(24.56)$ & \\
\hline $45-49$ & $125(20.90)$ & $47(19.83)$ & & $213(23.23)$ & $84(24.85)$ & \\
\hline $50-54$ & $112(18.73)$ & $55(23.21)$ & & 169 (18.43) & $64(18.93)$ & \\
\hline $55-59$ & $98(16.39)$ & $38(16.03)$ & & $110(12.00)$ & 37 (10.95) & \\
\hline $60+$ & $163(27.26)$ & $54(22.78)$ & & $193(21.05)$ & $70(20.71)$ & \\
\hline Height (cm) & $169.53 \pm 5.82$ & $169.45 \pm 6.46$ & 0.773 & $157.55 \pm 5.41$ & $157.68 \pm 5.71$ & 0.635 \\
\hline Weight $^{\mathrm{a}}(\mathrm{kg})$ & $73.02 \pm 11.82$ & $75.81 \pm 13.47$ & 0.005 & $61.65 \pm 9.38$ & $63.93 \pm 9.77$ & $<0.0001$ \\
\hline $\mathrm{BMI}^{\mathrm{a}}\left(\mathrm{kg} / \mathrm{m}^{2}\right)$ & $25.37 \pm 3.62$ & $26.36 \pm 4.05$ & 0.001 & $24.82 \pm 3.47$ & $25.73 \pm 3.88$ & $<0.0001$ \\
\hline Current residence & & & 0.012 & & & 0.043 \\
\hline Urban & $543(90.80)$ & $201(84.81)$ & & 847 (92.37) & $300(88.76)$ & \\
\hline Rural & $55(9.20)$ & $36(15.19)$ & & $70(7.63)$ & $38(11.24)$ & \\
\hline Birthplace & & & $<0.0001$ & & & $<0.0001$ \\
\hline Urban & $281(46.99)$ & $41(17.30)$ & & $436(47.55)$ & $89(26.33)$ & \\
\hline Rural & $317(53.01)$ & $196(82.70)$ & & $481(52.45)$ & 249 (73.67) & \\
\hline $\begin{array}{l}\text { Time spent in rural } \\
\operatorname{areas}^{\mathrm{b}}(\mathrm{y})\end{array}$ & $16.84 \pm 20.22$ & $26.88 \pm 19.80$ & $<0.0001$ & $16.04 \pm 19.12$ & $22.59 \pm 19.10$ & $<0.0001$ \\
\hline Education & & & 0.004 & & & $<0.0001$ \\
\hline $\begin{array}{l}\text { Primary school } \\
\text { or less }\end{array}$ & $74(12.37)$ & $28(11.81)$ & & $207(22.57)$ & $63(18.64)$ & \\
\hline Middle/high school & $329(55.02)$ & $103(43.46)$ & & $552(60.20)$ & $157(46.45)$ & \\
\hline $\begin{array}{l}\text { Undergraduate/ } \\
\text { graduate }\end{array}$ & $195(32.61)$ & $106(44.73)$ & & $158(17.23)$ & $118(34.91)$ & \\
\hline Hypertension & $263(43.98)$ & $123(51.90)$ & 0.039 & 303 (33.04) & $130(38.46)$ & 0.073 \\
\hline Diabetes $^{\mathrm{c}}$ & $77(12.88)$ & $30(12.66)$ & 0.932 & $70(7.65)$ & $15(7.84)$ & 0.046 \\
\hline Smoking status & & & 0.011 & & & $<0.0001$ \\
\hline Never & $143(23.91)$ & 77 (32.49) & & $881(96.07)$ & $305(90.24)$ & \\
\hline Past or current & $455(76.09)$ & $160(67.51)$ & & $36(3.93)$ & $33(9.76)$ & \\
\hline Alcohol consumption & & & 0.008 & & & 0.0005 \\
\hline Never & $138(23.08)$ & 35 (14.77) & & $782(85.28)$ & $260(76.92)$ & \\
\hline Past or current & $460(76.92)$ & $202(85.23)$ & & 135 (14.72) & $78(23.08)$ & \\
\hline Activity level & & & 0.002 & & & 0.690 \\
\hline Light & $14(2.34)$ & $0(0.00)$ & & $25(2.73)$ & $8(1.39)$ & \\
\hline Moderate & 489 (81.77) & $215(90.72)$ & & $848(92.48)$ & $310(91.30)$ & \\
\hline Heavy & $95(15.89)$ & $22(9.28)$ & & $44(4.80)$ & $20(7.30)$ & \\
\hline
\end{tabular}

${ }^{a}$ Thirteen participants were missing weight and BMI data

${ }^{\mathrm{b}}$ Fourteen participants were missing questionnaire data regarding relocation dates

${ }^{\mathrm{c}}$ Three participants were missing blood glucose data; hypertension is marked when average systolic blood pressure $\geq 140 \mathrm{mmHg}$ or average diastolic blood pressure $\geq 90 \mathrm{mmHg}$

The $\chi^{2}$ test and Mann-Whitney test were used to evaluate the demographic differences between Han and Mongolian people 
$p<0.001$; high myopia, $4.4 \%$ vs. $1.5 \%, p=0.003$ ), but the prevalence of hyperopia was lower in the Han population than in the Mongolian population $(25.8 \%$ vs. $35.3 \%, p=$ 0.002) (details in Supplemental Table 1).

\section{Distribution of RE in different age groups}

Participants involved in the final analysis were divided into five age groups: $40-44,45-49,50-54,55-59$ and $60+$ years old. The mean SE increased with age in both Han and Mongolian populations (Fig. 1a). The incidence of myopia decreased with age in both Han and Mongolian populations, while the incidence of hyperopia increased (Fig. 1b). The distribution of RE in the age groups from 45-49 $(p=0.001)$ and $50-54$ years $(p<0.001)$ was different in Han and Mongolian participants (Fig. 1c).

\section{Risk factors for RE in all participants}

A multivariable logistic regression model was used to identify the risk factors for RE, and the results are presented in Table 2 and Fig. 2. Mongolian participants were less likely to have myopia than Han participants (odds ratio (OR), 0.63; 95\% CI, 0.49-0.82; $p=0.001$ ) after adjusting for age, sex, height, time spent in rural areas, education level, activity level, presence of pterygium in the same eye, and smoking habits. Participants aged 45-49 years (OR, $0.65 ; 95 \%$ CI, $0.49-0.87 ; p=0.003), 50-54$ years (OR, $0.47 ; 95 \% \mathrm{CI}, 0.34-0.64 ; p<0.001)$ and $55-59$ years (OR, $0.46 ; 95 \%$ CI, $0.32-0.68 ; p<0.001)$ had a lower risk of myopia than those aged $40-44$ years. The length of time spent in rural areas (OR, 0.99; 95\% CI, 0.98-0.99; $p<$ 0.001 ) was identified as a protective factor against myopia. Conversely, a higher education level was found to be a risk factor for myopia. Compared with the ORs of participants with an education level of primary school or less, the OR for those with a middle/high school education level was 1.52 (95\% CI, 1.05-2.20; $p=0.027$ ), and the OR for those with an undergraduate/graduate education level reached 3.77 (95\% CI, 2.47-5.75; $p<0.001$ ).

Ethnicity was significantly associated with the onset of hyperopia. Mongolian participants were more likely to have hyperopia than Han participants (OR, 1.62; 95\% CI, $1.23-2.13 ; p=0.001)$ after adjustment for age, sex, height, time spent in rural areas, education level, activity level, presence of pterygium in the same eye, and smoking habits. Age was also related to the incidence of hyperopia, and elderly people tended to have hyperopia. Patients in all other age groups had a higher prevalence of hyperopia than those aged 40-44 years (45-49 years, $p=0.016$; others $p<$ 0.001). Height was identified as protective factors for hyperopia (OR, 0.97; 95\% CI, 0.95-0.99; $p=0.015$ ). Furthermore, we found that the presence of pterygium was a
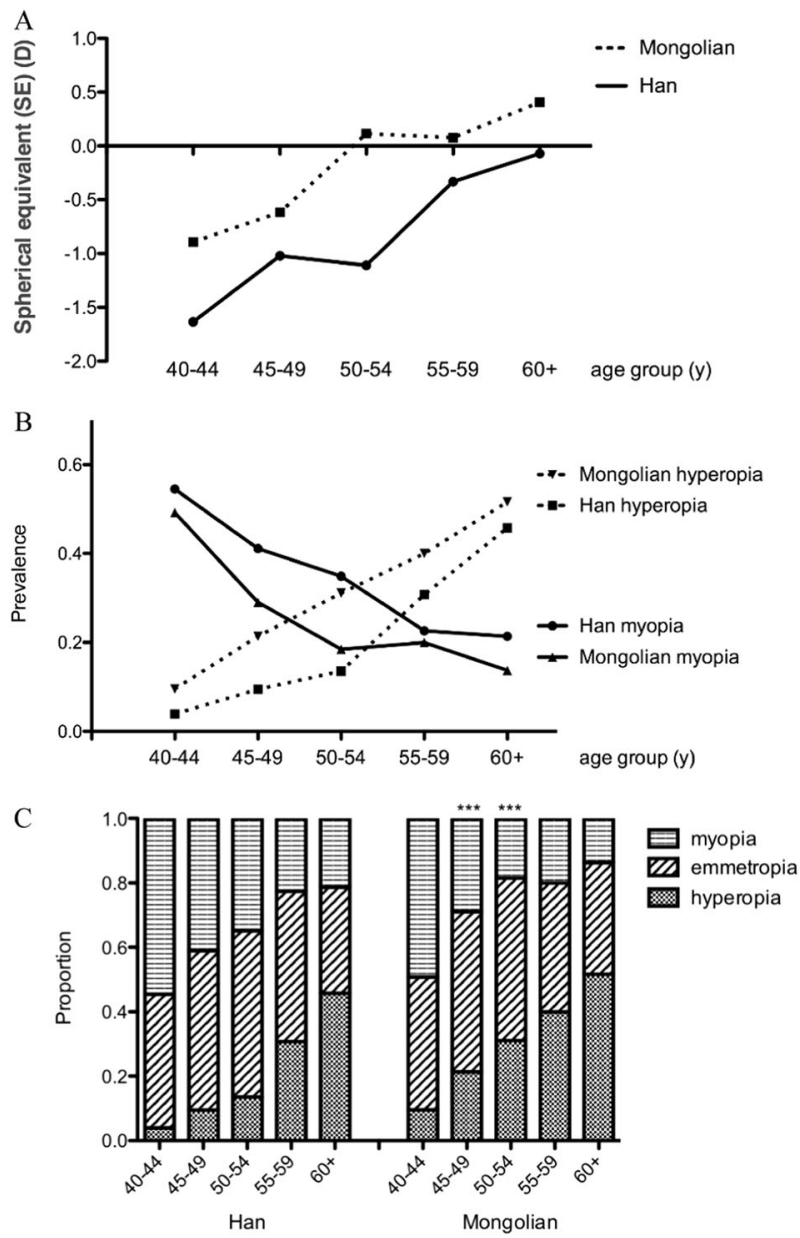

Fig. 1 SE, prevalence and distribution of RE in different age groups in Han and Mongolian populations notes: a SE in different age groups in Han and Mongolian populations; $\mathbf{b}$ Prevalence of RE in different age groups in Han and Mongolian populations; $\mathbf{c}$ Distribution of RE in different age groups in Han and Mongolian populations. Chi-square tests were used to evaluate the differences in the distribution of the prevalence of RE between Han and Mongolian populations $\left(^{*} p<0.05\right.$, $* * p<0.01, * * * p<0.001)$

risk factor and increased the prevalence of hyperopia (OR, 1.92 ; $95 \%$ CI, $1.14-3.23 ; p=0.014)$.

\section{Han versus Mongolian adults}

Ethnicity was found to be consistently associated with the prevalence of myopia and hyperopia. Furthermore, multivariable logistic regression analyses were performed to evaluate participants with different ethnic backgrounds (Table 3).

Table 3a presents the results of the multivariable logistic regression analysis of risk factors for myopia in Han and Mongolian populations. The risk factors for myopia are generally similar in Han and Mongolian populations. Participants aged 45-49 years (Han OR, 0.70; 95\% CI, $0.50-0.97 ; p=0.032$; Mongolian OR, $0.50 ; 95 \% \mathrm{CI}$, 
Table 2 Multivariable regression analysis of the right eye in all participants

\begin{tabular}{|c|c|c|c|c|c|c|c|c|}
\hline & \multicolumn{4}{|c|}{ Myopia $(\mathrm{SE}<-0.5 \mathrm{D}, n=695)$} & \multicolumn{4}{|c|}{ Hyperopia $(\mathrm{SE}>0.5 \mathrm{D}, n=481)$} \\
\hline & Odds ratio & $\begin{array}{l}95 \% \\
\text { CI lower }\end{array}$ & $\begin{array}{l}95 \% \\
\text { CI upper }\end{array}$ & $P$-value & Odds ratio & $\begin{array}{l}95 \% \\
\text { CI lower }\end{array}$ & $\begin{array}{l}95 \% \\
\text { CI upper }\end{array}$ & $P$-value \\
\hline $\begin{array}{l}\text { Ethnicity } \\
\text { (Mongolian/Han) }\end{array}$ & 0.63 & 0.49 & 0.82 & 0.001 & 1.62 & 1.23 & 2.13 & 0.001 \\
\hline \multicolumn{9}{|l|}{ Age range $(y)$} \\
\hline $40-44$ & 1.00 & & & & 1.00 & & & \\
\hline $45-49$ & 0.65 & 0.49 & 0.87 & 0.003 & 1.87 & 1.12 & 3.11 & 0.016 \\
\hline $50-54$ & 0.47 & 0.34 & 0.64 & $<0.001$ & 2.52 & 1.53 & 4.17 & $<0.001$ \\
\hline $55-59$ & 0.46 & 0.32 & 0.68 & $<0.001$ & 5.25 & 3.17 & 8.70 & $<0.001$ \\
\hline $60+$ & 0.70 & 0.50 & 1.00 & 0.051 & 9.25 & 5.71 & 14.99 & $<0.001$ \\
\hline Sex (female/male) & 1.26 & 0.85 & 1.88 & 0.251 & 0.80 & 0.52 & 1.24 & 0.313 \\
\hline Height (cm) & 0.99 & 0.97 & 1.01 & 0.248 & 0.97 & 0.95 & 0.99 & 0.015 \\
\hline $\begin{array}{l}\text { Time spent in } \\
\text { rural areas }(y)\end{array}$ & 0.99 & 0.98 & 0.99 & $<0.001$ & 1.00 & 0.99 & 1.01 & 0.801 \\
\hline \multicolumn{9}{|l|}{ Education } \\
\hline $\begin{array}{l}\text { Primary school } \\
\text { or less }\end{array}$ & 1.00 & & & & 1.00 & & & \\
\hline $\begin{array}{l}\text { Middle/ } \\
\text { high school }\end{array}$ & 1.52 & 1.05 & 2.20 & 0.027 & 0.79 & 0.57 & 1.10 & 0.163 \\
\hline $\begin{array}{l}\text { Undergraduate/ } \\
\text { graduate }\end{array}$ & 3.77 & 2.47 & 5.75 & $<0.001$ & 0.81 & 0.52 & 1.24 & 0.332 \\
\hline Activity level & 0.77 & 0.55 & 1.08 & 0.131 & 0.92 & 0.63 & 1.34 & 0.658 \\
\hline $\begin{array}{l}\text { Pterygium (with/ } \\
\text { without) }\end{array}$ & 1.09 & 0.60 & 1.99 & 0.775 & 1.92 & 1.14 & 3.23 & 0.014 \\
\hline $\begin{array}{l}\text { Smoking status } \\
\text { (smokers/non- } \\
\text { smokers) }\end{array}$ & 1.12 & 0.80 & 1.56 & 0.508 & 1.17 & 0.82 & 1.66 & 0.398 \\
\hline
\end{tabular}

A multivariable logistic regression model with nine indicators including ethnicity, age range, sex, height, length of time spent in rural areas, education level, activity level, presence of pterygium in the same eye and smoking status was used to assess the risk factors for myopia and hyperopia. The results for myopia and hyperopia were compared with those of emmetropic individuals
$0.28-0.89 ; p=0.018)$ and $50-54$ years (Han OR, 0.50; 95\% CI, 0.35-0.71; $p<0.001$; Mongolian OR, 0.35; 95\% CI, $0.18-0.67 ; p=0.002$ ) have a lower risk of myopia than those aged 40-44 years in both Han and Mongolian populations. Higher education level was a risk factor for myopia in both Han and Mongolian populations. The length of time spent in rural areas was found to be protective against myopia in the Han population (OR, 0.99; 95\% CI, 0.98-0.99; $p=0.001$ ) but not in the Mongolian population.

Table $3 \mathrm{~b}$ presents the results of the multivariable logistic regression analysis of risk factors for hyperopia in the Han and Mongolian populations. Age was a risk factor that was significantly related to the occurrence of hyperopia in both Han and Mongolian populations. In the Han population, those aged 45-49 years had an increased risk of hyperopia compared to those aged 40-44 years (OR, 2.07; 95\% CI, $1.04-4.11 ; p=0.038$ ). However, in the Mongolian population, the risk for hyperopia in those aged 45-49 or 50-54 years was not increased compared with that in those aged
$40-44$ years $(45-49$ years, $p=0.293 ; 50-54$ years, $p=$ $0.123)$.

\section{Discussion}

Our cross-sectional study assessed the prevalence of and identified risk factors for RE in Han and Mongolian populations located in the same area, namely, the Inner Mongolian Autonomous Region in mainland China. Ethnicity is associated with myopia and hyperopia after adjustment for age, sex, height, length of time spent in rural areas, education level, activity level, presence of pterygium and smoking habits. The distribution of RE worldwide differs among different ethnicities and areas [8]. Pan et al. [30] investigated 10033 Chinese, Indian and Malay Singaporeans and found that the Chinese had the highest risk of myopia and lowest risk of hyperopia compared with the Malays and Indians. Our study found that in the same region in Inner Mongolia, Han ethnicity was a risk factor for 
Fig. 2 Results of the multivariate logistic regression analyses for myopia and hyperopia notes: a Results of the multivariate logistic regression analysis of myopia; $\mathbf{b}$ Results of the multivariate logistic regression analysis of hyperopia. A multivariate logistic regression model with nine indicators including ethnicity, age range, sex, height, length of time spent in rural areas, education level, activity level, presence of pterygium in the same eye, and smoking status was used to assess risk factors for myopia and hyperopia. The myopia/hyperopia results were compared to emmetropic individuals. The OR of ethnicity was Mongolian/Han. The OR of sex was female/male. The OR of pterygium was eyes with pterygium/eyes without pterygium. The OR of smoking was smokers/never smokers
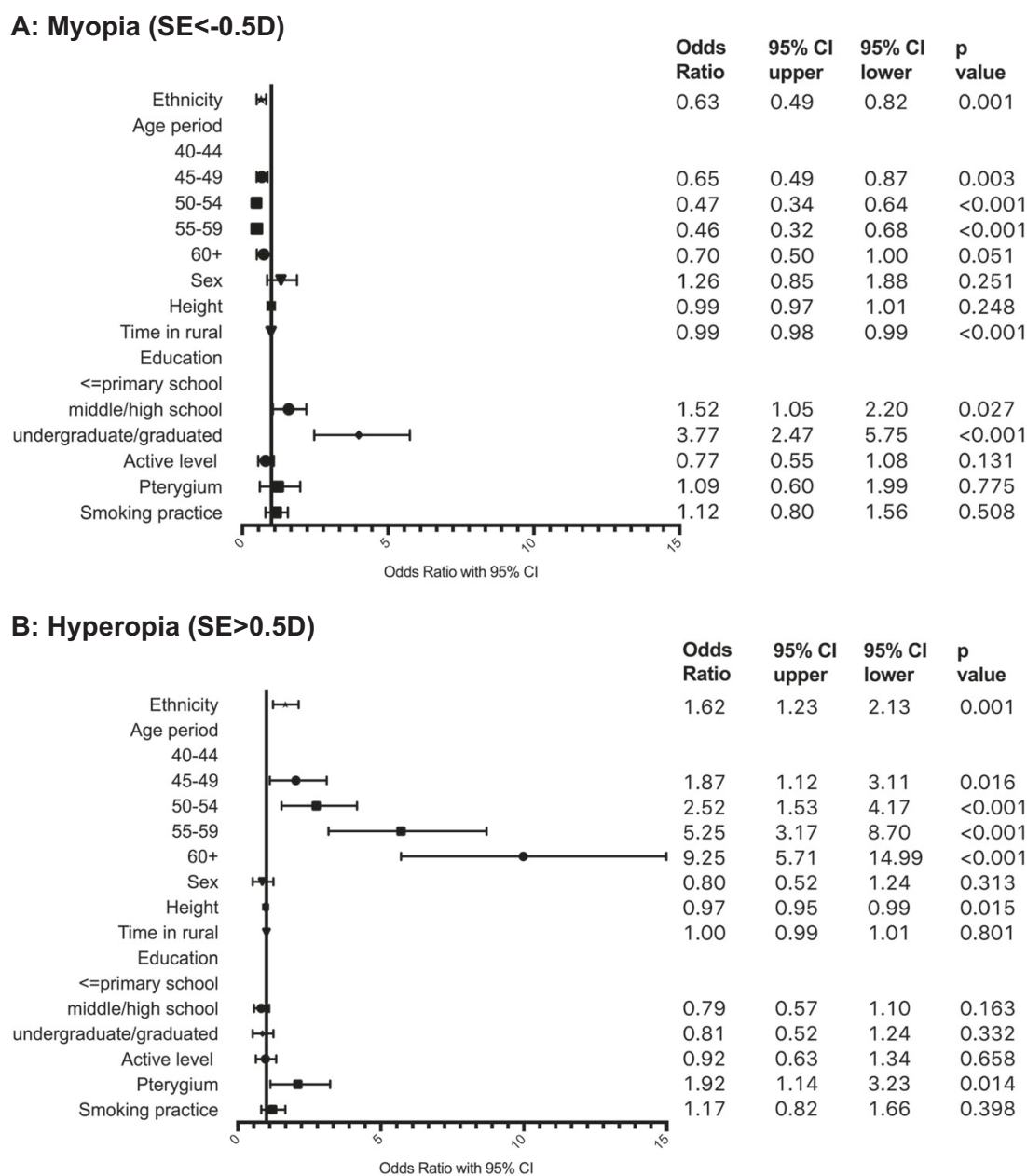

myopia, whereas Mongolian ethnicity was a risk factor for hyperopia. Apart from indicators included in our study, differences between Han and Mongolian populations have also been found in their genetic background [10, 1517, 31], diet [18], alcohol consumption [32], sleeping habits $[33,34]$, body structure $[35,36]$ and morphological traits [37]. The differences in the prevalence of and risk factors for RE in the Han and Mongolian populations could not be explained by the differences in the risk factors investigated in this study.

In adults aged 40 years and older, the SE and the proportion of those with hyperopia increased, whereas the proportion of those with myopia decreased in both the Han and Mongolian populations. This result is consistent with the normal ageing process [38]. The age-adjusted prevalence of myopia in all participants in our study was $29.4 \%$ (95\% CI, 27.4-31.3\%), which was lower than the prevalence of myopia among Chinese Singaporeans $(38.7 \%)$ [39], Malay Singaporeans (30.7\%) [40] and Japanese located in Tajimi (41.8\%) [41] (all participants aged $40+$ years; myopia was defined as an SE $<-0.5 \mathrm{D})$.
Wickremasinghe et al. [19] performed an epidemiological study involving 1800 Mongolian individuals aged $40+$ years and showed that the prevalence of myopia (defined as an SE $<-0.5 \mathrm{D})$ was only $17.2 \%$, the prevalence of hyperopia (defined as an $\mathrm{SE}>0.5 \mathrm{D}$ ) was $32.9 \%$, and the prevalence of high myopia (defined as an SE $<-5 \mathrm{D}$ ) was $2.7 \%$. Moreover, the researchers pointed out that the prevalence of myopia in Mongolia is much lower than other East Asian populations but close to western countries [19]. Our study also noticed that the prevalence of RE in the Mongolian population in Inner Mongolia in mainland China was similar to that in the Mongolian population in Mongolia. Interestingly, Bai et al. [10] recently reported that Mongolians share a high level of genetic identity by descent with Europeans by whole-genome sequencing of Mongolians.

Ethnicity, age, length of time spent in rural areas, and education level were found to be associated with the occurrence of myopia in our study. In Beijing, Guo et al. [24] found that rural residency was associated with a decreased risk of myopia compared with urban residency 
Table 3a Multivariable regression of myopia in Han and Mongolian populations

\begin{tabular}{|c|c|c|c|c|c|c|c|c|}
\hline & \multicolumn{4}{|c|}{$\operatorname{Han}(n=541)$} & \multicolumn{4}{|c|}{ Mongolian $(n=154)$} \\
\hline & Odds ratio & $\begin{array}{l}95 \% \\
\text { CI lower }\end{array}$ & $\begin{array}{l}95 \% \\
\text { CI upper }\end{array}$ & $P$-value & Odds ratio & $\begin{array}{l}95 \% \\
\text { CI lower }\end{array}$ & $\begin{array}{l}95 \% \\
\text { CI upper }\end{array}$ & $P$-value \\
\hline \multicolumn{9}{|l|}{ Age range $(y)$} \\
\hline $40-44$ & 1.00 & & & & 1.00 & & & \\
\hline $45-49$ & 0.70 & 0.50 & 0.97 & 0.032 & 0.50 & 0.28 & 0.89 & 0.018 \\
\hline $50-54$ & 0.50 & 0.35 & 0.71 & $<0.001$ & 0.35 & 0.18 & 0.67 & 0.002 \\
\hline $55-59$ & 0.43 & 0.28 & 0.67 & $<0.001$ & 0.56 & 0.26 & 1.22 & 0.146 \\
\hline $60+$ & 0.75 & 0.50 & 1.11 & 0.151 & 0.59 & 0.27 & 1.29 & 0.186 \\
\hline Sex (female/male) & 1.38 & 0.86 & 2.22 & 0.179 & 0.96 & 0.45 & 2.05 & 0.925 \\
\hline Height $(\mathrm{cm})$ & 0.98 & 0.96 & 1.01 & 0.190 & 0.99 & 0.95 & 1.03 & 0.601 \\
\hline $\begin{array}{l}\text { Time spent in } \\
\text { rural areas }(y)\end{array}$ & 0.99 & 0.98 & 0.99 & 0.001 & 0.99 & 0.97 & 1.00 & 0.079 \\
\hline \multicolumn{9}{|l|}{ Education } \\
\hline $\begin{array}{l}\text { Primary school } \\
\text { or less }\end{array}$ & 1.00 & & & & 1.00 & & & \\
\hline $\begin{array}{l}\text { Middle/ } \\
\text { high school }\end{array}$ & 1.45 & 0.96 & 2.19 & 0.074 & 1.75 & 0.70 & 4.39 & 0.234 \\
\hline $\begin{array}{l}\text { Undergraduate/ } \\
\text { graduate }\end{array}$ & 3.90 & 2.40 & 6.33 & $<0.001$ & 3.66 & 1.41 & 9.48 & 0.008 \\
\hline Activity level & 0.71 & 0.49 & 1.03 & 0.069 & 1.33 & 0.58 & 3.04 & 0.504 \\
\hline $\begin{array}{l}\text { Pterygium (with/ } \\
\text { without) }\end{array}$ & 1.01 & 0.50 & 2.03 & 0.979 & 1.43 & 0.43 & 4.76 & 0.557 \\
\hline $\begin{array}{l}\text { Smoking status } \\
\text { (smokers/non- } \\
\text { smokers) }\end{array}$ & 1.30 & 0.87 & 1.93 & 0.198 & 0.79 & 0.42 & 1.47 & 0.457 \\
\hline
\end{tabular}

A multivariable logistic regression model with eight indicators including age range, sex, height, length of time spent in rural areas, education level, activity level, presence of pterygium in the same eye and smoking status was used to assess risk factors for myopia. The results were compared to emmetropic individuals
(OR, 0.17; $p<0.001)$. An Australian study involving 2367 children revealed that the prevalence of myopia in an inner city region was greater than that in an outer suburban region (17.8\% vs. 6.9\%) [42]. Birthplace and current place of residence were combined into one indicator in our study, namely, time spent in rural areas, which was found to be associated with a decreased risk of myopia $(p<0.001)$. Apart from the indicators controlled in our multivariable model, urban residency might also bring higher individual income, professional or office-related occupations, and more contact with electronic devices. It is widely accepted that higher education level increases the risk of myopia $[7,8,43]$. The mechanism of myopia as a complex of genetics and environmental factors is still unknown, and researchers think that an individual's genetic risk of myopia is significantly influenced by their education level [44]. Moreover, educational attainment is strongly influenced by genes and should not be solely considered as an environmental risk factor [45]. Outdoor activities have also been indicated to reduce the risk of myopia [46, 47]. Moreover, a recent study revealed that outdoor activities play a greater role in decreasing the risk of myopia than the young-age near-work activity model that was previously touted [6].
Our study found no influence of different activity levels on the risk of myopia $(p=0.131)$, which confirmed that it is "outdoor" rather than "activities" that really matters. Recent studies found that sunlight outdoors might increase the release of retinal dopamine which is protective from axial elongation in experimental myopia [47, 48].

In addition to an association with ethnicity, associations between hyperopia and age, height and the presence of pterygium were also noticed in our study. The prevalence of hyperopia increases with age. Moreover, when analyses were performed separately for the Han and Mongolian populations, the risk of hyperopia in the Han participants was already increased in those aged 45-49 years compared with those aged 40-44 years. In the Mongolian population, the risk of hyperopia increased only after individuals reached 55-59 years. The progression of hyperopia starts earlier in the Han population than in the Mongolian population. The Liwan Eye Study in Guangzhou, China suggested that the rates of hyperopia started to increase in those aged 60-69 years, which is similar to the Japanese but later than the Singaporean Chinese and white and black Baltimore populations [49]. Fewer studies investigate the prevalence of hyperopia, and the exact pattern of hyperopia 
Table 3b Multivariable regression of hyperopia in Han and Mongolian populations

\begin{tabular}{|c|c|c|c|c|c|c|c|c|}
\hline & \multicolumn{4}{|c|}{$\operatorname{Han}(n=310)$} & \multicolumn{4}{|c|}{ Mongolian $(n=171)$} \\
\hline & Odds ratio & $\begin{array}{l}95 \% \\
\text { CI lower }\end{array}$ & $\begin{array}{l}95 \% \\
\text { CI upper }\end{array}$ & $P$-value & Odds ratio & $\begin{array}{l}95 \% \\
\text { CI lower }\end{array}$ & $\begin{array}{l}95 \% \\
\text { CI upper }\end{array}$ & $P$-value \\
\hline \multicolumn{9}{|l|}{ Age range $(y)$} \\
\hline $40-44$ & 1.00 & & & & 1.00 & & & \\
\hline $45-49$ & 2.07 & 1.04 & 4.11 & 0.038 & 1.53 & 0.69 & 3.36 & 0.293 \\
\hline $50-54$ & 2.87 & 1.46 & 5.64 & 0.002 & 1.85 & 0.85 & 4.05 & 0.123 \\
\hline $55-59$ & 6.89 & 3.56 & 13.31 & $<0.001$ & 3.06 & 1.32 & 7.08 & 0.009 \\
\hline $60+$ & 13.81 & 7.32 & 26.03 & $<0.001$ & 3.89 & 1.76 & 8.64 & 0.001 \\
\hline Sex (female/male) & 0.98 & 0.55 & 1.76 & 0.951 & 0.55 & 0.27 & 1.10 & 0.089 \\
\hline Height $(\mathrm{cm})$ & 0.98 & 0.95 & 1.01 & 0.120 & 0.96 & 0.92 & 0.99 & 0.024 \\
\hline $\begin{array}{l}\text { Time spent in } \\
\text { rural areas }(y)\end{array}$ & 1.00 & 0.99 & 1.01 & 0.894 & 1.00 & 0.99 & 1.01 & 0.955 \\
\hline \multicolumn{9}{|l|}{ Education } \\
\hline $\begin{array}{l}\text { Primary school } \\
\text { or less }\end{array}$ & 1.00 & & & & 1.00 & & & \\
\hline $\begin{array}{l}\text { Middle/ } \\
\text { high school }\end{array}$ & 0.73 & 0.49 & 1.08 & 0.113 & 0.99 & 0.54 & 1.82 & 0.969 \\
\hline $\begin{array}{l}\text { Undergraduate/ } \\
\text { graduate }\end{array}$ & 1.09 & 0.63 & 1.90 & 0.750 & 0.56 & 0.27 & 1.17 & 0.123 \\
\hline Activity level & 0.84 & 0.53 & 1.31 & 0.437 & 1.16 & 0.57 & 2.36 & 0.688 \\
\hline $\begin{array}{l}\text { Pterygium (with/ } \\
\text { without) }\end{array}$ & 1.85 & 0.98 & 3.48 & 0.059 & 2.10 & 0.80 & 5.55 & 0.133 \\
\hline $\begin{array}{l}\text { Smoking status } \\
\text { (smokers/non- } \\
\text { smokers) }\end{array}$ & 1.27 & 0.79 & 2.04 & 0.322 & 1.11 & 0.64 & 1.92 & 0.712 \\
\hline
\end{tabular}

A multivariable logistic regression model with eight indicators including age range, sex, height, length of time spent in rural areas, education level, activity level, presence of pterygium in the same eye and smoking status was used to assess risk factors for hyperopia. The results were compared to emmetropic individuals with age is still unclear [50]. Our study also suggested that height is a protective factor against hyperopia. Previous studies [22-26] have indicated that body stature, especially height, is associated with axial length, which is a possible explanation of our finding. Similar to previous studies [51, 52], our study also found that the presence of pterygium was associated with an increased risk of hyperopia (OR, $1.92 ; p=0.014)$. Eyes with myopia have a thinner cornea, thinner sclera and more redundant conjunctiva than eyes with hyperopia, which might be protective against the development of pterygium [53-55]. Moreover, pterygium is a type of eye disease that is related to old age [56]. Considering that old age is one of the risk factors for hyperopia, it can be speculated that age might contribute to the relationship between pterygium and hyperopia.

The strengths of our study include a relatively large sample size and reasonable response rate which is $94 \%$. However, as a cross-sectional study, we were unable to establish a causal relationship between the various risk factors and RE. Cohort studies are needed in the future. Moreover, more detailed information, including daily outdoor time, nutritional intake, and sleeping habits, could be included in the questionnaire. Indices of ocular biometric data, such as axial length, should be included in future studies to investigate the prevalence of refractive myopia and axial myopia in Han and Mongolian populations.

\section{Conclusion}

Our cross-sectional study is the first to investigate the prevalence of and risk factors for RE in Han and Mongolian adults living in the same area, namely, the Inner Mongolian Autonomous Region in mainland China. Mongolian ethnicity was a protective factor against myopia but a risk factor for hyperopia. Additionally, age, time spent in rural areas, and education level were found to be risk factors for myopia. Age, height and the presence of pterygium were found to be associated with hyperopia. Our study assessed the prevalence of and risk factors for RE among participants of different ethnicities living in the same region. We investigated the difference of prevalence of and risk factors for RE between the Han and Mongolian populations, which could not be explained by differences in the risk factors investigated in this study. 


\section{Summary}

\section{What was known before:}

- Mongols are an East-Central Asian ethnic group native to Mongolia and China's Inner Mongolia.

- Mongolian in Mongolia have a lower prevalence of myopia compared to other East Asian areas.

\section{What this study adds:}

- Compared to Han population in the same area in Inner Mongolia of China, Mongolian population have a lower myopia risk and higher hyperopia risk.

- Age, time spent in rural areas, and education level were found to be risk factors for myopia. Age, height and the presence of pterygium were found to be associated with hyperopia.

Acknowledgements We thank Guoju Li, Ke Wang, Fen Dong, Haiying Gong, Guodong Xu, Yanlong Li, Bin Wang, and Guangjin Zhu for their assistance in data collection. This study was supported by the National Science and Technology Pillar Program during the Twelfth Five-Year Plan Period sponsored by the Ministry of Science and Technology of China (Grant 2012BAI37B02). The authors alone are responsible for the content of the paper.

Funding National Science and Technology Pillar Program during the Twelfth Five-Year Plan Period sponsored by the Ministry of Science and Technology of China (Grant 2012BAI37B02)

\section{Compliance with ethical standards}

Conflict of interest The authors declare that they have no conflict of interest.

Publisher's note: Springer Nature remains neutral with regard to jurisdictional claims in published maps and institutional affiliations.

\section{References}

1. Naidoo KS, Leasher J, Bourne RR, Flaxman SR, Jonas JB, Keeffe $\mathrm{J}$, et al. Global vision impairment and blindness due to uncorrected refractive error, 1990-2010. Optom Vis Sci. 2016;93:227-34.

2. Vitale S, Cotch MF, Sperduto RD. Prevalence of visual impairment in the United States. JAMA. 2006;295:2158-63.

3. Pizzarello L, Abiose A, Ffytche T, Duerksen R, Thulasiraj R, Taylor H, et al. VISION 2020: the right to sight: a global initiative to eliminate avoidable blindness. Arch Ophthalmol. 2004;122:615-20.

4. Lougheed T. Myopia: the evidence for environmental factors. Environ Health Perspect. 2014;122:A12-A19.

5. Ramamurthy D, Chua SYL, Saw SM. A review of environmental risk factors for myopia during early life, childhood and adolescence. Clin Exp Optom. 2015;98:497-506.
6. Hornbeak DM, Young TL. Myopia genetics: a review of current research and emerging trends. Curr Opin Ophthalmol. 2009;20:356-62.

7. Pan CW, Ramamurthy D, Saw SM. Worldwide prevalence and risk factors for myopia. Ophthalmic Physiol Opt. 2012;32:3-16.

8. Wojciechowski R. Nature and nurture: the complex genetics of myopia and refractive error. Clin Genet. 2011;79:301-20.

9. Tabulation on the 2010 population census of the People's Republic of China. http://www.stats.gov.cn/tjsj/pcsj/rkpc/6rp/ indexch.htm. 2010.

10. Bai H, Guo X, Narisu N, Lan T, Wu Q, Xing Y, et al. Wholegenome sequencing of 175 Mongolians uncovers populationspecific genetic architecture and gene flow throughout North and East Asia. Nat Genet. 2018;50:1696-704.

11. Li G, Wang H, Wang K, Wang W, Dong F, Qian Y, et al. Prevalence, awareness, treatment, control and risk factors related to hypertension among urban adults in Inner Mongolia 2014: differences between Mongolian and Han populations. BMC Public Health. 2016;16:294.

12. Bai Z, Yang X, Han X, Dong P, Liu A. Comparison between coronary plaque 64-slice spiral CT characteristics and risk factors of coronary artery disease patients in Chinese Han population and Mongolian. Pak J Med Sci. 2013;29:933-7.

13. Li N, Wang H, Yan Z, Yao X, Hong J, Zhou L. Ethnic disparities in the clustering of risk factors for cardiovascular disease among the Kazakh, Uygur, Mongolian and Han populations of Xinjiang: a cross-sectional study. BMC Public Health. 2012;12:499.

14. Huriletemuer Zhang C, Zhao S, Wang D, Wang Z, Jiang M, et al. An epidemiological study of stroke and its sub-types in the over 55 Mongolian and Han populations in a pastoral area of inner Mongolia. Int J Stroke. 2011;6:468.

15. Jiang XY, Chang FH, Bai TY, Lv XL, Wang MJ. Susceptibility of lung cancer with polymorphisms of CYP1A1, GSTM1, GSTM3, GSTT1 and GSTP1 genotypes in the population of Inner Mongolia region. Asian Pac J Cancer Prev. 2014;15:5207-14.

16. Bai H, Liu H, Suyalatu S, Guo X, Chu S, Chen Y, et al. Association analysis of genetic variants with type 2 diabetes in a Mongolian population in China. $\mathrm{J}$ Diabetes Res. 2015;2015:613236.

17. Qin L, Zhao P, Liu Z, Chang P. Associations SELE gene haplotype variant and hypertension in Mongolian and Han populations. Intern Med. 2015;54:287-93.

18. Komatsu F, Kagawa Y, Kawabata T, Kaneko Y, Purvee B, Otgon $\mathrm{J}$, et al. Dietary habits of Mongolian people, and their influence on lifestyle-related diseases and early aging. Curr Aging Sci. 2008;1:84-100.

19. Wickremasinghe S, Foster PJ, Uranchimeg D, Lee PS, Devereux JG, Alsbirk PH, et al. Ocular biometry and refraction in Mongolian adults. Invest Ophthalmol Vis Sci. 2004;45:776-83.

20. Zhao HX, Zhang L, Guan WY. Difference in normal corneal thickness and curvature between Mongolian and Han nationalities. Int J Ophthalmol. 2015;8:399-402.

21. He H, Pan L, Pa L, Cui Z, Ren X, Wang D et al. Data resource profile: the china national health survey (CNHS). Int J Epidemiol. 2018. https://doi.org/10.1093/ije/dyy1151.

22. Huang CY, Hou CH, Lin KK, Lee JS, Yang ML. Relationship of lifestyle and body stature growth with the development of myopia and axial length elongation in Taiwanese elementary school children. Indian J Ophthalmol. 2014;62:865-9.

23. Northstone K, Guggenheim JA, Howe LD, Tilling K, Paternoster L, Kemp JP, et al. Body stature growth trajectories during childhood and the development of myopia. Ophthalmology. 2013;120:1064-73.

24. Guo Y, Liu LJ, Xu L, Lv YY, Tang P, Feng Y, et al. Outdoor activity and myopia among primary students in rural and urban regions of Beijing. Ophthalmology. 2013;120:277-83. 
25. Tan CS, Chan YH, Wong TY, Gazzard G, Niti M, Ng TP, et al. Prevalence and risk factors for refractive errors and ocular biometry parameters in an elderly Asian population: the Singapore Longitudinal Aging Study (SLAS). Eye. 2011;25:1294-301.

26. Saw SM, Chua WH, Hong CY, Wu HM, Chia KS, Stone RA, et al. Height and its relationship to refraction and biometry parameters in Singapore Chinese children. Invest Ophthalmol Vis Sci. 2002;43:1408-13.

27. Saw SM, Chia KS, Lindstrom JM, Tan DT, Stone RA. Childhood myopia and parental smoking. Br J Ophthalmol. 2004;88:934-7.

28. Stone RA, Wilson LB, Ying GS, Liu C, Criss JS, Orlow J, et al. Associations between childhood refraction and parental smoking. Invest Ophthalmol Vis Sci. 2006;47:4277-87.

29. Rahi JS, Cumberland PM, Peckham CS. Myopia over the lifecourse: prevalence and early life influences in the 1958 British birth cohort. Ophthalmology. 2011;118:797-804.

30. Pan CW, Zheng YF, Anuar AR, Chew M, Gazzard G, Aung T, et al. Prevalence of refractive errors in a multiethnic Asian population: the Singapore epidemiology of eye disease study. Invest Ophthalmol Vis Sci. 2013;54:2590-8.

31. Bai H, Guo X, Zhang D, Narisu N, Bu J, Jirimutu J, et al. The genome of a Mongolian individual reveals the genetic imprints of Mongolians on modern human populations. Genome Biol Evol. 2014;6:3122-36.

32. Hu W, Tong WJ, Liu YB, Teng GX, Zhang YH. Correlation between alcohol intake and smoking and hypertension in Mongolian people. Chin J Public Health. 2006;22:2.

33. Muge K, Xi W, Degang Z, Shangli S. Rangeland nomadic culture of the Mongolian nationality (I)-origin, language and religion of the Mongolian nationality. Grass1 Turf. 2013;33:80-4.

34. Jiliang $X$. The research on fertility intention national differences and its influencing factors: from the comparison between the Han nationality and the Mongolian nationality. Popul J. 2015;37: 25-35.

35. Zhang Y, Zhang Z, Zhang J, He S, Liu Y, Zhang Y, et al. A cohort study on the relationship between different hip circumference levels and the events of cerebrovascular diseases and deaths in Mongolian peasants and herdsmen. Chin J Dis Control Prev. 2014;18:290-5.

36. Lin Z, Buren B, Jin X, Hasen G, Xiao J. Developments of height and weight in Mongolian students aged 6 to 18 years. Chin J Public Health. 2012;28:102-4.

37. Zheng L, Han Z, Lu S, Li Y, Shuyuan L. Morphological traits in peoples of Mongolian nationality of the Hulunbuir league, Inner Mongolia, China. Anthropol Anz. 2002;60:175-85

38. Papadopoulos PA, Papadopoulos AP. Current management of presbyopia. Middle East Afr J Ophthalmol. 2014;21:10-7.

39. Wong TY, Foster PJ, Hee J, Ng TP, Tielsch JM, Chew SJ, et al. Prevalence and risk factors for refractive errors in adult Chinese in Singapore. Invest Ophthalmol Vis Sci. 2000;41:2486-94.

40. Saw SM, Chan YH, Wong WL, Shankar A, Sandar M, Aung T, et al. Prevalence and risk factors for refractive errors in the Singapore Malay Eye Survey. Ophthalmology. 2008;115:1713-9.
41. Sawada A, Tomidokoro A, Araie M, Iwase A, Yamamoto T, Tajimi Study Group. Refractive errors in an elderly Japanese population: the Tajimi study. Ophthalmology. 2008;115:363-70.

42. Ip JM, Rose KA, Morgan IG, Burlutsky G, Mitchell P. Myopia and the urban environment: findings in a sample of 12-year-old Australian school children. Invest Ophthalmol Vis Sci. 2008;49:3858-63.

43. Morgan IG, Ohno-Matsui K, Saw SM. Myopia. Lancet. 2012;379:1739-48.

44. Verhoeven VJ, Buitendijk GH, Rivadeneira F, Uitterlinden AG, Vingerling JR.Consortium for Refractive Error and Myopia (CREAM) et al. Education influences the role of genetics in myopia. Eur J Epidemiol. 2013;28:973-80.

45. Dirani M, Shekar SN, Baird PN. The role of educational attainment in refraction: the Genes in Myopia (GEM) twin study. Invest Ophthalmol Vis Sci. 2008;49:534-8.

46. Jin JX, Hua WJ, Jiang X, Wu XY, Yang JW, Gao GP, et al. Effect of outdoor activity on myopia onset and progression in schoolaged children in northeast China: the Sujiatun Eye Care Study. BMC Ophthalmol. 2015;15:73.

47. Sherwin JC, Hewitt AW, Coroneo MT, Kearns LS, Griffiths LR, Mackey DA. The association between time spent outdoors and myopia using a novel biomarker of outdoor light exposure. Invest Ophthalmol Vis Sci. 2012;53:4363-70.

48. McCarthy CS, Megaw P, Devadas M, Morgan IG. Dopaminergic agents affect the ability of brief periods of normal vision to prevent form-deprivation myopia. Exp Eye Res. 2007;84:100-7.

49. He M, Huang W, Li Y, Zheng Y, Yin Q, Foster PJ. Refractive error and biometry in older Chinese adults: the Liwan eye study. Invest Ophthalmol Vis Sci. 2009;50:5130-6.

50. American Academy of Ophthalmology. Clinical optics, 2016-7. American Academy of Ophthalmology: San Francisco; 2016.

51. Shiroma H, Higa A, Sawaguchi S, Iwase A, Tomidokoro A, Amano S, et al. Prevalence and risk factors of pterygium in a southwestern island of Japan: the Kumejima Study. Am J Ophthalmol. 2009;148:766-71.

52. Lim CY, Kim SH, Chuck RS, Lee JK, Park CY. Risk factors for pterygium in Korea: the Korean National Health and Nutrition Examination Survey V, 2010-2012. Medicine. 2015;94: e1258.

53. Linke SJ, Steinberg J, Eddy MT, Richard G, Katz T. Relationship between minimum corneal thickness and refractive state, keratometry, age, sex, and left or right eye in refractive surgery candidates. J Cataract Refract Surg. 2011;37:2175-80.

54. Jonas JB, Xu L. Histological changes of high axial myopia. Eye. 2014;28:113-7.

55. Mimura T, Usui T, Yamagami S, Funatsu H, Noma H, Toyono T, et al. Relationship between conjunctivochalasis and refractive error. Eye Contact Lens. 2011;37:71-8.

56. Chen T, Ding L, Shan G, Ke L, Ma J, Zhong Y. Prevalence and racial differences in pterygium: a cross-sectional study in Han and Uygur adults in Xinjiang, China. Invest Ophthalmol Vis Sci. 2015;56:1109-17. 